\title{
'SELF-ORGANIZING MAP ANALYSIS OF AGENTS' EXPECTATIONS. DIFFERENT PATTERNS OF ANTICIPATION OF THE 2008 FINANCIAL CRISIS"
}




\section{I $|\mathrm{R}| \mathrm{E}|\mathrm{A}|$}

Institut de Recerca en Economia Aplicada Regional i Públic

Research Institute of Applied Economics

WEBSITE: www.ub-irea.com•CONTACT: irea@ub.edu

\section{AQR}

Grup de Recerca Anàlisi Quantitativa Regional

Regional Quantitative Analysis Research Group

WEBSITE: www.ub.edu/aqr/•CONTACT: $\underline{\text { aqr@ub.edu }}$

\section{Universitat de Barcelona}

Av. Diagonal, $690 \cdot 08034$ Barcelona

The Research Institute of Applied Economics (IREA) in Barcelona was founded in 2005, as a research institute in applied economics. Three consolidated research groups make up the institute: AQR, RISK and GiM, and a large number of members are involved in the Institute. IREA focuses on four priority lines of investigation: (i) the quantitative study of regional and urban economic activity and analysis of regional and local economic policies, (ii) study of public economic activity in markets, particularly in the fields of empirical evaluation of privatization, the regulation and competition in the markets of public services using state of industrial economy, (iii) risk analysis in finance and insurance, and (iv) the development of micro and macro econometrics applied for the analysis of economic activity, particularly for quantitative evaluation of public policies.

IREA Working Papers often represent preliminary work and are circulated to encourage discussion. Citation of such a paper should account for its provisional character. For that reason, IREA Working Papers may not be reproduced or distributed without the written consent of the author. A revised version may be available directly from the author.

Any opinions expressed here are those of the author(s) and not those of IREA. Research published in this series may include views on policy, but the institute itself takes no institutional policy positions. 
By means of Self-Organizing Maps we cluster fourteen European countries according to the most suitable way to model their agents' expectations. Using the financial crisis of 2008 as a benchmark, we distinguish between those countries that show a progressive anticipation of the crisis and those where sudden changes in expectations occur. By mapping the trajectory of economic experts' expectations prior to the recession we find that when there are brisk changes in expectations before impending shocks, Artificial Neural Networks are more suitable than time series models for modelling expectations. Conversely, in countries where expectations show a smooth transition towards recession, ARIMA models show the best forecasting performance. This result demonstrates the usefulness of clustering techniques for selecting the most appropriate method to model and forecast expectations according to their behaviour..

JEL classification: C02; C22; C45; C63; E27.

Keywords: Business surveys; Self-Organizing Maps; Clustering; Forecasting; Neural networks; Time series models; Nonlinear models

Oscar Claveria. AQR Research Group-IREA. Department of Econometrics. University of Barcelona, Av. Diagonal 690, 08034 Barcelona, Spain. E-mail: oclaveria@ub.edu

Enric Monte. Department of Signal Theory and Communications, Polytechnic University of Catalunya. Email: enric.monte@upc.edu

Salvador Torra. Department of Econometrics \& Riskcenter-IREA, Universitat de Barcelona, Av. Diagonal 690, 08034 Barcelona, Spain. E-mail: storra@ub.edu

\section{Acknowledgements}

We wish to thank Ann Stangl and Johanna Plenk at the Ifo Institute for Economic Research in Munich for providing us the data used in the study. This work was supported by the Ministerio de Economía y Competitividad under the SpeechTech4All Grant (TEC2012-38939-C03-02). 


\section{INTRODUCTION}

Anticipating economic expectations is of upmost importance in order to assess the current state of the economy. Tendency surveys provide detailed information about agents' perceptions and expectations. The fact that survey results are based on the knowledge of the respondents operating in the market and are rapidly available makes them very valuable for forecasting purposes and decision-making. Survey results are presented as weighted percentages of respondents expecting a variable to go up, to go down or to remain unchanged. The qualitative nature of survey results has often lead to quantify agents' responses making use of survey indicators, such as the balance statistic. See Lahiri and Zhao (2015) for an appraisal of alternative measures of economic expectations. The fact that survey results are based on the knowledge of the respondents operating in the market and are rapidly available makes them very valuable for forecasting purposes and decision-making.

Anticipating agents' expectations has become essential to forecast the evolution of the economy as they are increasingly used as explanatory variables in quantitative forecasting models, nevertheless there are very few studies of short-run forecasting of Business Survey Indicators (Clar et al., 2007; Ghonghadze and Lux, 2009). Such an exercise allows to select the forecasting technique that shows the best forecasting performance (Hendry and Clements, 2003; Stock and Watson, 2003). Expectations forecasts can then be used to predict business cycle turning points (Qi, 2001; Diebold and Rudebusch, 1989), to quantify business survey data (Lahiri and Zhao, 2015; Breitung, and Schmeling, 2013; Claveria et al., 2006; Mitchell, 2002; Mitchell et al., 2002) and as explanatory variables in quantitative forecasts models (Guizzardi and Stacchini, 2015; Lui et al., 2011; Graff, 2010; Mitchell et al., 2005; Claveria et al., 2007, 2010; Parigi and Schlitzer, 1995; Biart and Praet, 1987).

Many authors have acknowledged the importance of applying new approaches to forecasting in order to improve the accuracy of the methods of analysis (Buchen and Wohlrabe, 2013; Robinzonov et al., 2012; Song and Li, 2008). The availability of more advanced forecasting techniques has led to a growing interest Artificial Intelligence (AI) methods (Cang and Yu, 2014; Pai et al., 2014; Celotto et al., 2012; Chen, 2011; Lin et al., 2011; Goh et al., 2008; Yu and Schwartz, 2006) to the detriment of time series models (Chu, 2008, 2011) and causal econometric models (Franses et al., 2011). Some 
of the new AI based techniques are fuzzy time series models (Tsaur and Kuo, 2011), Support Vector Machines (SVMs) (Kao et al., 2013) and ANNs. Recent research has shown the suitability of ANNs for dealing with time series forecasting (Fioramanti, 2008; Sermpinis et al., 2012; Claveria et al., 2014, 2016).

This study extends previous research by Claveria and Torra (2013), who generate short-run forecasts of business survey indicators of the World Economic Survey (WES) carried out quarterly by the Ifo Institute for Economic Research. The authors compare the forecasting accuracy of an Artificial Neural Network (ANN) model to that of three different time series models (AR, ARIMA and SETAR) for fourteen European countries and find no significant differences between ANNs and ARIMA in most cases. Based on the classification of countries for which the authors obtain better forecasting results with ANNs for each of the main variables of the WES, we aim to explain why nonlinear models present a better forecasting performance in some countries.

By means of a Self-Organizing Map (SOM) analysis we map the evolution of economic experts' expectations during the transition to the 2008 financial crisis. This AI-based technique allows us to classify the fourteen European countries into two groups according to the changing perceptions of their economic experts during the pre and post-crisis quarters: those in which the shock is gradually anticipated, and those where a brisk change in expectations occurs. Finally, by overlapping the forecasting results with these two clusters, we find that the most suitable way to model expectations in each country is connected to the behaviour of experts' expectations before the impending crisis.

SOMs use unsupervised training algorithms and belong to a general class of ANNs based on nonlinear regression techniques that can be trained to organize data so as to disclose so far unknown patterns or structures (Deboeck and Kohonen, 1988). SOMs have been used in order to make visual predictions of different phenomena, but only recently in economic studies (Sarlin and Peltonen, 2013; Resta, 2012; Lu and Wang, 2010; Marghescu et al., 2010; Arciniegas-Rueda and Arciniegas, 2009; Eklund et al., 2008). In this study we make use of SOMs to analyze experts' expectations about the state of the economy in fourteen European countries before and after the financial crisis of 2008. SOMs allow us to cluster all countries according to whether their experts' anticipated the crisis and to analyze whether there are significant differences across countries regarding the behaviour of agents' expectations. 
To our knowledge, this is the first study to apply SOMs to expectations measured by survey indicators. We use the raw data from all the indicators of the three main variables of the WES: the country's general situation regarding overall economy, capital expenditures and private consumption. We also compare the results for three different types of expectations: the present judgement, the present situation compared to same time last year, and the expected situation by the end of the next six months. The data set includes 18 quarterly indicators and 18 quarterly composite indicators (balance and weighted balance statistics) of each country for the period ranging from 1989 to 2008.

ANNs have powerful pattern classification capabilities (Sarlin and Marghescu, 2011) and have been applied in many fields (Bahmanyar and Karami, 2014; Kang and Cho, 2014; Kaushika et al., 2014). ANNs can be classified into feed-forward networks and recurrent networks depending on the connecting patterns of the different layers of neurons. In feed-forward networks the information runs only in one direction, whilst in recurrent networks there are feedback connections from outer layers of neurons to lower layers of neurons. Feed-forward networks were the first ANNs devised. The Multi-layer perceptron (MLP) network is the most widely used feed-forward topology in time series forecasting (Claveria and Torra, 2014; Lin et al., 2011, Palmer et al., 2006; Kon and Turner, 2005; Zhang and Qi, 2005; Tsaur et al., 2002). SOMs are feed-forward ANNs that use unsupervised training algorithms and belong to a general class of ANNs based on nonlinear regression techniques that allow to generate topological representations of the original data called maps.

The structure of the paper is as follows. Section 2 presents our methodological approach. The data set of survey indicators is described in Section 3. In Section 4 we undertake a SOM analysis of all the information and map agents' perceptions to determine the most appropriate way to model expectations. Conclusions are given in Section 5.

\section{METHODOLOGY - SELF-ORGANIZING MAP (SOM)}

ANNs are an AI-based technique that consist of interconnected processing units called neurons. They have a parallel distribution information processing device that allows them to approximate the mapping between input and output by nonlinear functions. ANNs learn from experience and they are able to capture functional relationships when the underlying process is unknown, as it happens with the data generating process of 
economic expectations. These features have brought us to use SOMs in order to cluster European countries according to their experts' expectations regarding the state of the economy during the crisis of 2008, which in turn allows us to test whether differences in expectations' behavior have an effect on the modeling procedure used to generate forecasts from tendency survey indicators.

The fact that ANNs are able to identify related temporal patterns by learning from historical data explains the great interest that ANNs have aroused for economic forecasting (Feng and Zhang, 2014; Kock and Teräsvirta, 2011, 2014; Pérez-Rodríguez et al., 2005, 2009; Nakamura, 2005; Qi, 2001; Cybenko, 1989; Funahashi, 1989; Hornik, Stinchcombe and White 1989; Wasserman, 1989, Adya and Collopy, 1998; Swanson and White, 1997; Kaastra and Boyd, 1996; Hill, Marquez, O’Connor and Remus, 1994). In the present study we compare the forecasting performance of a MLP ANN to that of different time series models, and we select the most suitable methodology to model and forecasts expectations based on the behavior recorded.

SOM is a special type of feed-forward ANN model that uses an unsupervised learning algorithms based on the idea of the similarity between inputs and weights (Kohonen, 1982, 2001). SOMs may be considered a nonlinear generalization of Principal Components Analysis (PCA) that have many advantages over the conventional feature extraction methods (Liu and Weisberg, 2005). SOM models consist of a two-layer architecture: in the first layer (input layer) information is distributed, while in the second layer (output layer) the map is made. The final output is usually represented in a two-dimensional map of neurons (see Figure 1). Therefore, SOMs can be regarded as representations of similitude relations in data.

Figure 1 represents the architecture of a Kohonen network, in which each column in the grid represents a neuron. Each neuron has as many weights as the input descriptors for the objects to be mapped into the network. The training phase in a SOM consists of adjusting the weights in a competitive iterative process. The winning neuron is that with the most similar weights to the input descriptors. The weights are then corrected so that they become more similar to the input descriptors (measudred by the smallest distance metric). Then neurons are classified during the mapping phase according to the class of the objects that are mapped. This process allow SOMs for a nonlinear projection of a high-dimensional space (inputs) onto a discrete space (output) represented by the wining neurons. Therefore, SOM analysis can be regarded as method for exploratory data analysis that illustrates data structures in easily understandable forms. 
Figure 1. Architecture of a Kohonen Self-Organizing Map

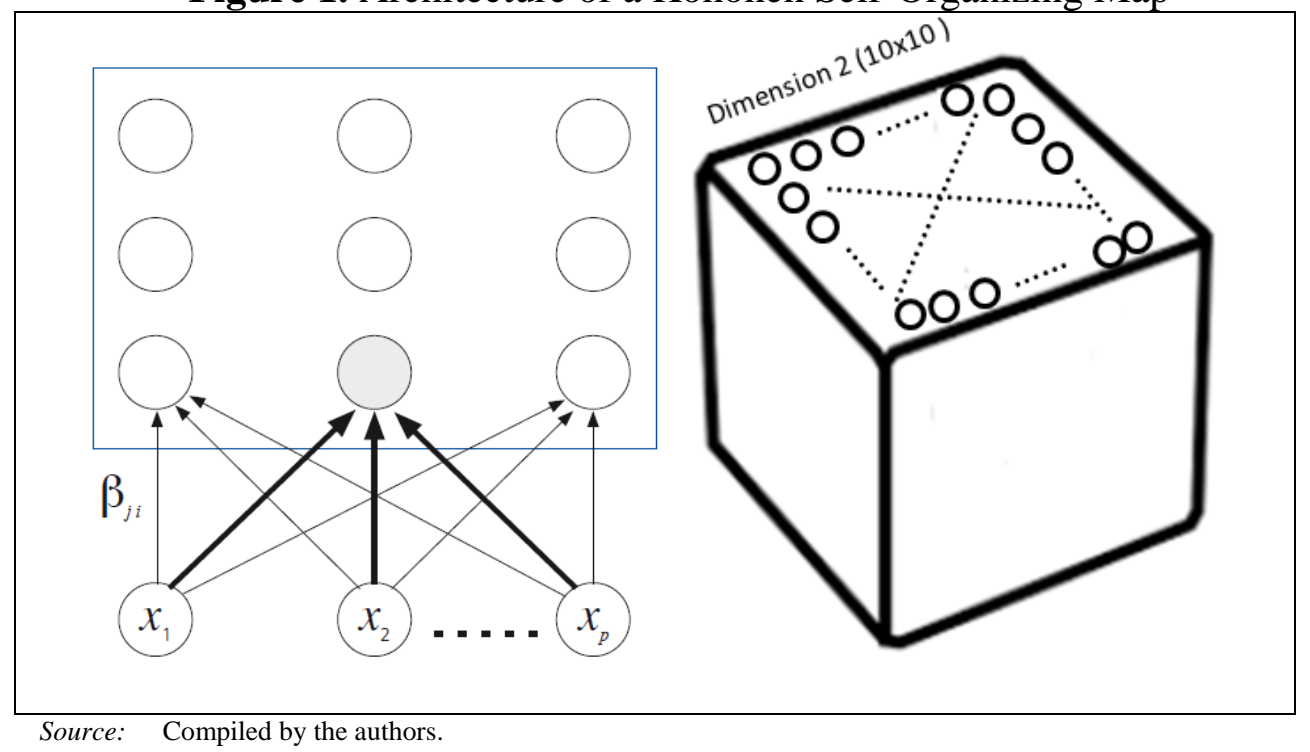

\section{DATA - SURVEY INDICATORS}

In the present study we use agent's expectations from the World Economic Survey (WES) carried out quarterly by the Ifo Institute for Economic Research. The WES assesses worldwide economic trends by polling organisations worldwide on current economic developments in their respective countries, allowing for a rapid assessment of the economic situation prevailing around the world. In April 2011, 1107 economic experts in 120 countries were polled. The survey questionnaire focuses on qualitative information: assessments of a country's general situation and expectations regarding important economic indicators. The survey results are published as aggregated data. The aggregation procedure is based on country classifications. Within each country group or region, the country results are weighted according to the share of the specific country's exports and imports in total world trade (CESifo World Economic Survey, 2011). For a detailed analysis of WES data see Stangl (2008).

Tendency surveys have become an essential tool for gathering information about a wide range of economic variables, as they provide very detailed information about agents' perceptions and expectations. Survey results are presented as weighted percentages of respondents expecting a variable to go up, to go down or to remain unchanged. As a result, tendency surveys contain two pieces of independent information 
at time $t, R_{t}$ and $F_{t}$, denoting the percentage of respondents at time $t-1$ expecting an economic variable to rise or fall at time $t$. The information therefore refers to the direction of change but not to its magnitude.

The qualitative nature of survey results has often lead to quantify them making use of business survey indicators. The most commonly used indicator to present survey results is the balance statistic:

$$
B_{t}=R_{t}-F_{t}
$$

Assuming that the expected percentage change in a variable remains constant over time for agents reporting an increase and for those reporting a decrease, Anderson (1951) defined the balance statistic as a measure of the average changes expected in the variable. As the balance statistic $\left(B_{t}\right)$ does not take into account the percentage of respondents expecting a variable to remain constant $\left(C_{t}\right)$, Claveria (2010) proposed a nonlinear variation of the balance statistic ( $W B_{t}$, weighted balance) that accounts for this percentage of respondents:

$$
W B_{t}=\frac{R_{t}-F_{t}}{R_{t}+F_{t}}=\frac{B_{t}}{1-C_{t}}
$$

Weighting the balance statistic by the proportion of respondents expecting a variable to rise or fall allows discriminating between two equal values of the balance statistic depending on the percentage of respondents expecting a variable to remain constant.

The experiment is based on all the information available for the first three questions of the WES: the country's general situation regarding overall economy, capital expenditures and private consumption. For each question we in turn used three different kind of expectations stated by the agents: their present judgement, their judgement compared to same time last year and their expectation by the end of the next six months. The dataset analysed includes therefore 9 indicators for each country: the $B_{t}$ for each of the three different expectations (present judgement, compared to same time last year, expected situation by the end of the next six months) of each question. We use information from fourteen countries of the European Union: Austria, Belgium, Denmark, Finland, France, Germany, Greece, Ireland, Italy, the Netherlands (NL), Portugal, Sweden and the United Kingdom (UK). 


\section{SELF-ORGANIZING MAP ANALYSIS OF AGENTS’ EXPECTATIONS}

As SOMs can be regarded as method for exploratory data analysis that illustrates data structures in easily understandable forms, we have make use of this feature to characterize the temporal evolution of the expectations before and during the beginning of the financial crisis of 2008. Our data set encompasses answers from year 1989 to year 2008, with a total of 80 samples per country. As a result the database consisted of 1022 samples. In order to asses the capacity of the network to model the behaviour of the expectations, we divide the database into a training database, which consists of the first 73 samples per country (i.e. from the first quarter of year 1989 to the fourth quarter of the year 2006), and 8 samples per country for testing (i.e. from the first quarter of 2007 to the fourth quarter of 2008). Therefore, the SOM is trained with data from all 14 countries in the aforementioned period.

SOMs cluster the data, but also have the property of arranging the clusters by similarity on a plane. Therefore there is an interpolation aspect in the estimation of the centroids. In order to make use of this property, and to have enough granularity on the map, we take a 10x10 topology, which yielded 100 centroids and approximately 10 samples per centroid. In order to capture well the topological property of neighbourhood of the centroids, we use an alpha that ranges from 0.05 to 0.0001 along 15000 iterations of the algorithm. The neighbourhood function is taken to be rectangular. We use the 'Kohonen' package implemented in R (Wehrens and Buydens, 2007) and Matlab. For the test database, we present the trajectories of each country along the nearest centroids for each sample (Figure 2a and 2b).

This analysis is based on overlapping the temporal evolution of the agents' expectations on a map. Figures $2 \mathrm{a}$ and $2 \mathrm{~b}$ show the evolution of expectations represented by the balance statistic at the beginning of the financial crisis of 2008 in fourteen countries of the European Union (Austria, Belgium, Denmark, Finland, France, Germany, Greece, Ireland, Italy, the Netherlands, Portugal, Sweden and the United Kingdom). These maps allow us to determine different trajectories in order to discriminate between countries with respect of their agents' perception of the imminent crisis. 
Figure 2a. Trajectories of Balances $\left(B_{t}\right)$ from I:2007 to IV:2008

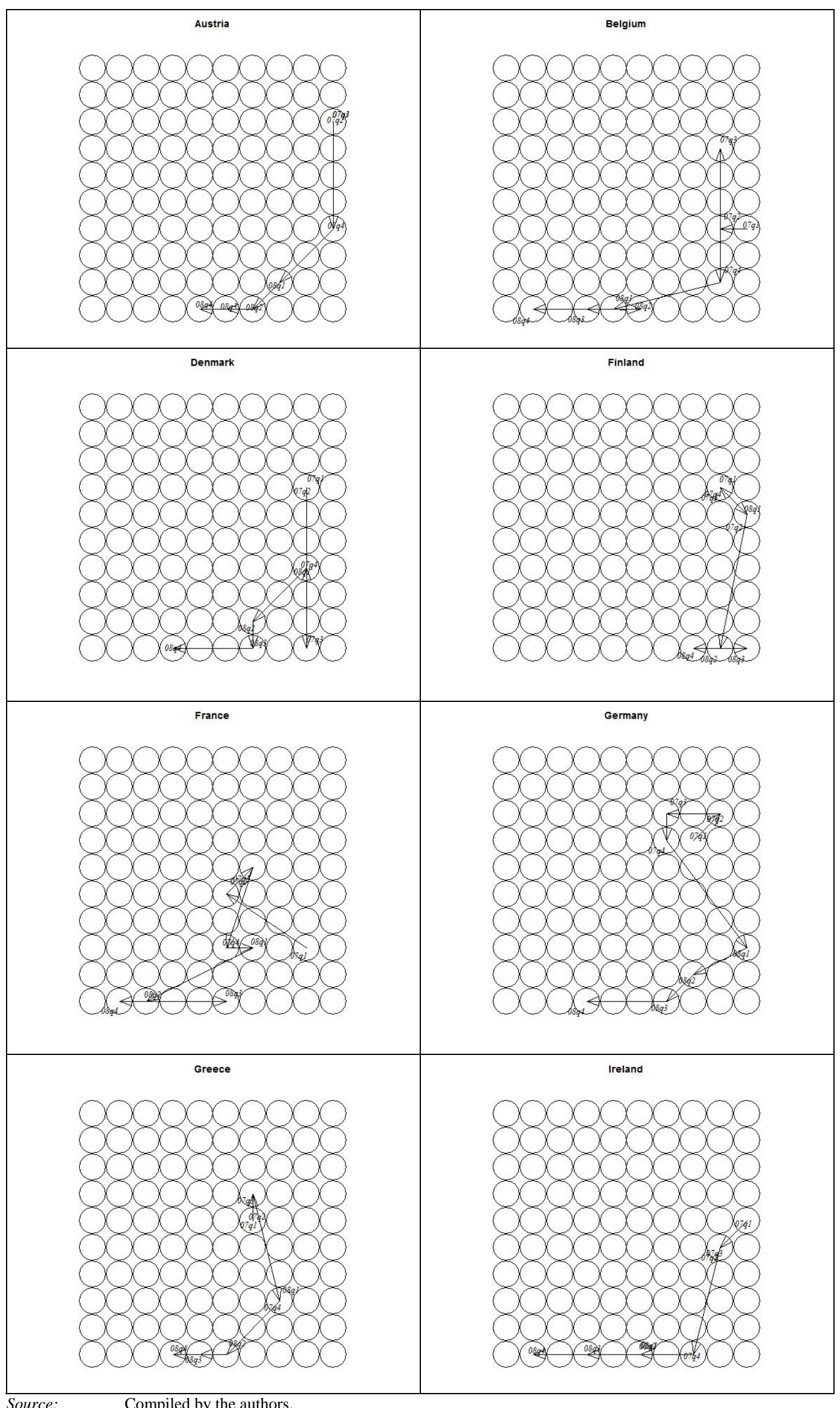


Figure 2b. Trajectories of Balances ( $B_{t}$ ) from I:2007 to IV:2008

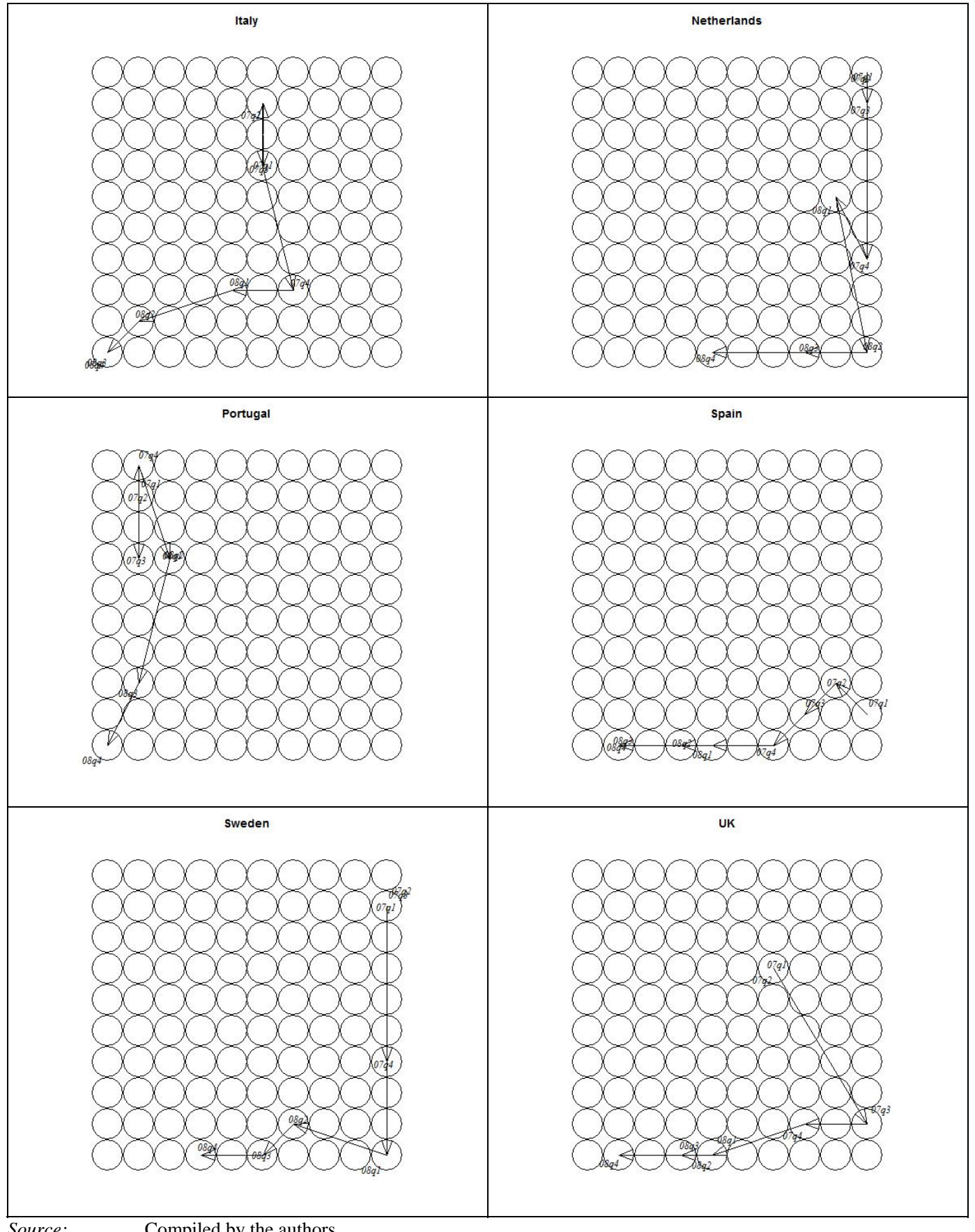

The SOMs in Figures 3, 4 and 5 represent the information regarding the balances for each of the three questions (the country's general situation regarding overall economy, capital expenditures and private consumption) and for each type of expectations (experts' present judgement, judgement compared to same time last year and expectation by the end of the next six months). 
Figure 3. SOMs of Balances $\left(B_{t}\right)$ (I:2007 to IV:2008) for Present judgement expectations (for each question)

\begin{tabular}{|c|c|c|c|c|c|c|c|c|}
\hline \multicolumn{9}{|c|}{ Present judgment } \\
\hline \multicolumn{9}{|c|}{ This country's general situation regarding overall economy } \\
\hline$-52.82-25.1$ & -62.5 & -7.56 & 5.02 & 28.84 & 55.28 & 55.97 & 90.92 & 88.92 \\
\hline$-62.34-24.25$ & -17.58 & -16.12 & 10.79 & 18.23 & 69.32 & 49.18 & 97.25 & 93.63 \\
\hline$-73.06-75.58$ & -41.87 & -14.53 & -6.26 & 37.84 & 48.87 & 67.56 & 87.93 & 71.1 \\
\hline$-91.45-75.84$ & -0.71 & 34.73 & 43.91 & 4.47 & 39.98 & 43.2 & 93.47 & 91.25 \\
\hline$-96.78-59.66$ & -33.88 & -27.96 & -8.23 & 12.25 & 30.42 & 53.14 & 70.86 & 98.19 \\
\hline \begin{tabular}{ll|l}
-84.96 & -70.4
\end{tabular} & -32.96 & -14.47 & -31.12 & 9.61 & 24.31 & 62.49 & 75.9 & 62.91 \\
\hline$-82.98-47.75$ & -51.48 & -47.65 & 7.4 & 19.38 & 19.71 & 19.4 & 48.07 & 71.05 \\
\hline$-95.15-87.17$ & -56.79 & -5.62 & -11.49 & 20.11 & 2.95 & 30.79 & 22.7 & 20.41 \\
\hline$-86.4-78.77$ & -72.78 & -2.11 & -0.23 & 3.78 & 41.58 & 38.3 & 25.8 & 54.71 \\
\hline$-97.65-84.28$ & -38.79 & -29.44 & -7.97 & 1.03 & 21.36 & 23.3 & 62.35 & 70.08 \\
\hline
\end{tabular}

This country's general situation regarding capital expenditures

\begin{tabular}{|l|l|l|l|l|l|l|l|l|l|}
\hline-70.11 & -50.34 & -31.77 & -21.11 & -48.3 & 27.99 & 5.81 & 12.1 & 46.8 & 73.08 \\
\hline-63.32 & -39.73 & 5.36 & 5.91 & 2.9 & -4.01 & 27.17 & 40.53 & 71.72 & 60.76 \\
\hline$-83.75-59.16$ & -16.5 & -7.17 & 15.97 & 1.92 & 43.67 & 11.98 & 81.02 & 56.97 \\
\hline$-91.53-62.71$ & -6.72 & -82.63 & -69.6 & 3.14 & 27.46 & 34.41 & 59.04 & 97.08 \\
\hline$-86.91-62.61$ & -55.8 & -32.61 & -30.43 & -20.43 & 3.92 & -2.93 & 39.07 & 77.76 \\
\hline$-81.81-68.96$ & -29.6 & -35.59 & -30.99 & -31.36 & -2.18 & 25.07 & 49.49 & 73.05 \\
\hline$-86.97-55.46$ & -49.57 & -64.86 & -10.8 & -10.4 & -3.28 & 21.58 & 51.76 & 65.55 \\
\hline-92 & -81.49 & -62.9 & -30.78 & -34.41 & 7.61 & -5.96 & 8.93 & 18.94 & 43.85 \\
\hline-96.69 & -78.29 & -74 & -25.49 & -10.28 & -44.78 & 4.98 & 30.28 & 10.16 & 35.46 \\
\hline
\end{tabular}

This country's general situation regarding private consumption

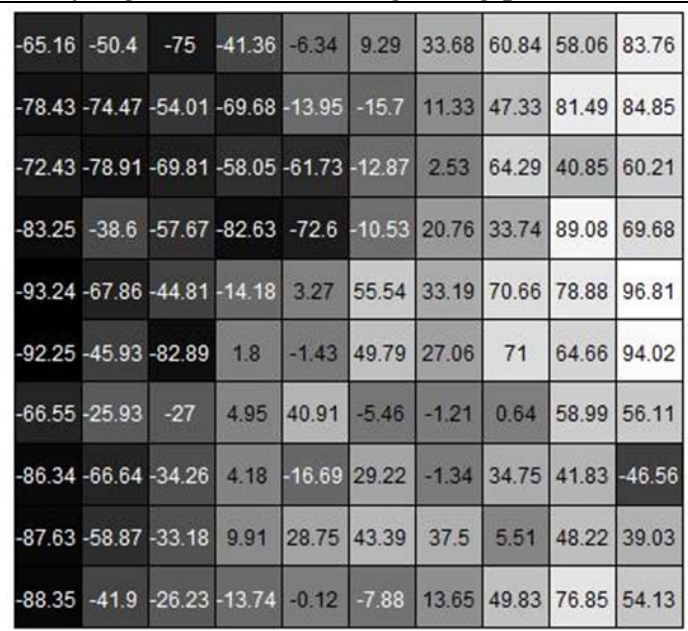

Source: Compiled by the authors. 
Figure 4. SOMs of Balances ( $\left.B_{t}\right)$ (I:2007 to IV:2008) for expectations regarding the Comparison to the same time last year (for each question)

Compared to same time last year

This country's general situation regarding overall economy

\begin{tabular}{|l|l|l|l|l|l|l|l|l|l|}
\hline 93.32 & 51.31 & 112.16 & 93.18 & 67.33 & 90.91 & 90.49 & 63.2 & 79.82 & 83.98 \\
\hline 31.36 & 63.56 & 85.68 & 65.89 & 74.52 & 54.92 & 78.53 & 45.77 & 42.2 & 83.49 \\
\hline 66.34 & 63.6 & 6.04 & 26.65 & 76.76 & 89.6 & 66.82 & 70.81 & 60.1 & 52.13 \\
\hline 12.48 & 35.26 & 20.79 & 17.37 & 48.34 & 44.76 & 52.51 & 66.6 & 55.45 & 91.25 \\
\hline-13.25 & -4.27 & -5.48 & -26.8 & 12.31 & 45.45 & 36.84 & 48.58 & 43.42 & 31.95 \\
\hline-44.4 & -51.63 & -45.95 & -32.65 & -56.9 & 0.08 & 18.8 & 5.5 & 14.44 & 14.97 \\
\hline-82.23 & -70.76 & -38.45 & -67.38 & -64.49 & -34.09 & -2.86 & -4.63 & -6.89 & 33.55 \\
\hline$-86.57-59.23$ & -79.76 & -75.18 & -51.11 & -35.8 & -11.43 & -10.33 & 2.41 & 54.17 \\
\hline-61.98 & -86.54 & -73.35 & -74.61 & -47.75 & -35.88 & -34.31 & -1.46 & -3.01 & 29.99 \\
\hline-89.88 & -101.1 & -92.5 & -86.57 & -57.29 & -53.18 & -42.11 & -50.19 & -10.76 & -4.49 \\
\hline
\end{tabular}

This country's general situation regarding capital expenditures

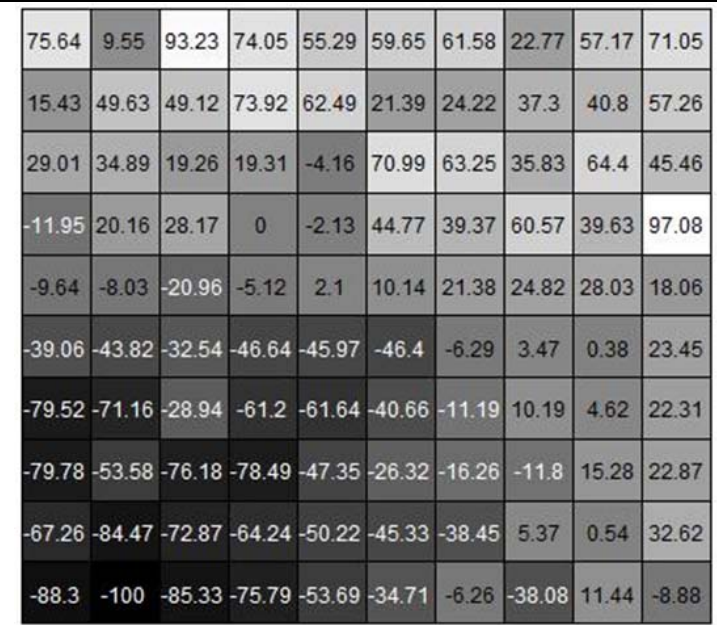

This country's general situation regarding private consumption

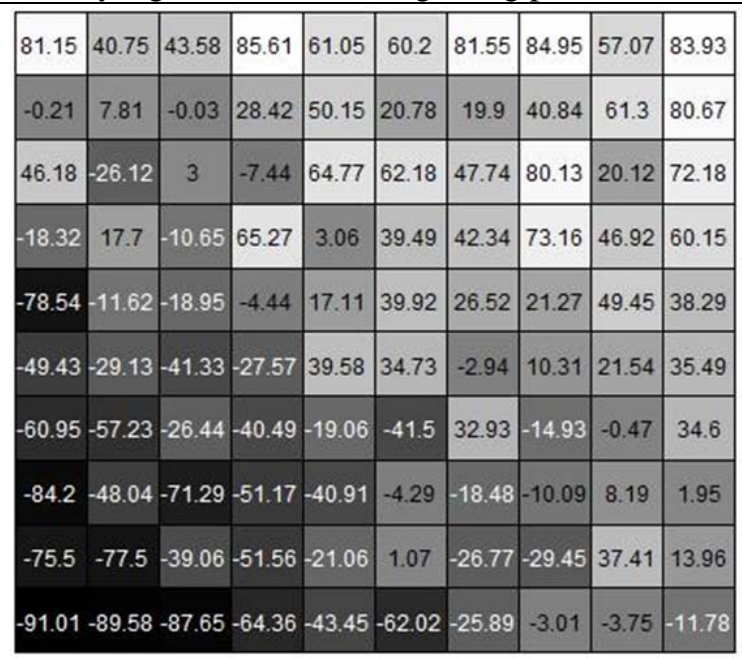

Source: Compiled by the authors. 
Figure 5. SOMs of Balances ( $\left.B_{t}\right)$ (I:2007 to IV:2008) for expectations regarding the Expected situation by the end of the next six months (for each question)

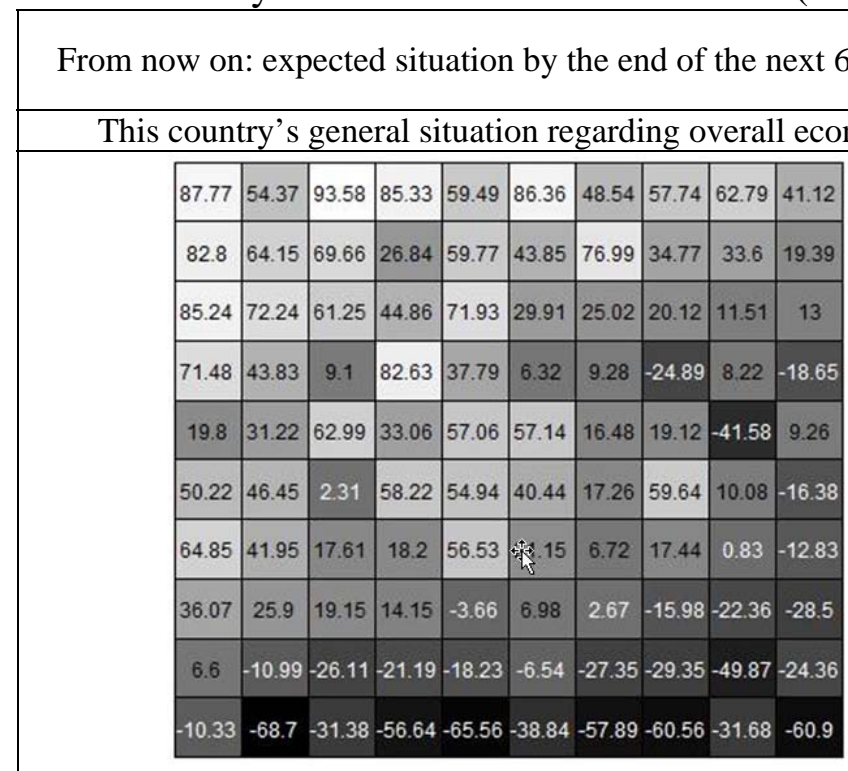

This country's general situation regarding capital expenditures

\begin{tabular}{|l|l|l|l|l|l|l|l|l|l|}
\hline 75.32 & 42.19 & 87.16 & 74.61 & 74.64 & 59.78 & 44.8 & 42.58 & 47.02 & 43.13 \\
\hline 68.25 & 61.58 & 56.53 & 15.87 & 49.43 & 30.46 & 20.63 & 29.15 & 34.11 & 11.28 \\
\hline 67.88 & 50.72 & 45.16 & 27.4 & 16.05 & 40.39 & 13.07 & 13.86 & 14.12 & 5.27 \\
\hline 54.42 & 27.4 & 20.04 & 117.37 & 53.96 & 6.24 & 8.57 & -22.01 & 11.23 & -23.5 \\
\hline 36.73 & 23.16 & 51.5 & 29.37 & 40.08 & 39.59 & 13.44 & 28.62 & -38.25 & 2.51 \\
\hline 38.44 & 44.38 & 15.4 & 40.7 & 42.57 & 23.23 & 7.89 & 42.11 & 13.02 & -7.97 \\
\hline 43.97 & 30.53 & 10.89 & 18.68 & -6.21 & 14.84 & -0.35 & 23.62 & 7.46 & -24.39 \\
\hline 15.42 & 15.44 & 16.91 & 12.23 & -4.84 & -11.81 & 4.9 & -21.55 & -4.35 & -41.27 \\
\hline 3.69 & -25.96 & -28.45 & -19.57 & -30.94 & -8.42 & -26.19 & -23.52 & -29.13 & -6.4 \\
\hline-34.16 & $-63.68-27.24$ & -58.32 & -57.25 & -28.08 & -54.51 & -52.3 & -22.28 & -60.98 \\
\hline
\end{tabular}

This country's general situation regarding private consumption

\begin{tabular}{|c|c|c|c|c|c|c|c|c|c|}
\hline 73.95 & 50.79 & 12.84 & 79.69 & 45.96 & 70.24 & 48.78 & 63.59 & 43.85 & 48.1 \\
\hline 65.53 & 43.02 & 2.42 & 46.35 & 53.93 & 35.32 & 8.34 & 32.2 & 45.37 & 24.02 \\
\hline 67.63 & -19.57 & 19.01 & 61.7 & 69.29 & 33.8 & 50.02 & 26.43 & 37.65 & 23.88 \\
\hline 43.62 & 14.65 & 7.48 & 100 & 27.67 & 10.92 & 5.66 & -19.14 & -2.93 & -36.35 \\
\hline-6.36 & 26.64 & 39.93 & 29.81 & 42.13 & 38.82 & 18.2 & -9.51 & -38.96 & 18.52 \\
\hline 47.95 & 26.49 & -3.32 & 35.32 & 44.27 & 17.86 & -4.79 & 35.38 & 5.31 & -35.7 \\
\hline 45.6 & 39.61 & 6.84 & 10.4 & 45.73 & 9.68 & 18.88 & 13.18 & -12.38 & 0 \\
\hline 9.86 & -3.44 & 0.77 & 8.96 & -6.04 & 8.93 & -13.69 & -17.96 & -23.39 & 0 \\
\hline-17.96 & -4.71 & -34.13 & -23.88 & -16.87 & -27.29 & -37.08 & -36.61 & -29.56 & -30.87 \\
\hline-55.88 & -29.51 & -33.6 & -48.33 & -54.79 & -36.49 & -61.29 & -53.28 & -48.35 & -66.84 \\
\hline
\end{tabular}

Source: Compiled by the authors. 
Each grid consists of 100 neurons of different sign. The positive signs indicate the prevalence of positive expectations with regard of negative expectations. The negative signs represent the reverse situation: there are more respondents expecting a decrease in the variable than respondents expecting an increase. The darker the cell, the higher the negative value of the neuron. Therefore, the darker areas represent the predominance of negative expectations. The maps in Figures 3, 4 and 5 allow us to distinguish between zones of maximum consensus (balances are similar) and zones where expectations present a wider range of discrepancy. The black and white neurons, unlike the grey ones, indicate maximum consensus, regardless of the sign.

Finally, in Figure 6 we cross temporal information with the SOM analysis displayed in Figures 2, 3, 4 and 5 and the forecasting results obtained by Claveria and Torra (2013). More specifically, we overlap the trajectories of the expectations for the next six months (from the first quarter of 2007 to the last quarter of 2008) on a different map for each of the three questions. The grey area indicates a predominance of negative expectations. The arrowheads coincide with the last period of analysis (IV:2008), once the perception of the crisis had definitely settled in all countries. The fact that all temporal trajectories end in the grey area is indicative of this shared belief.

The three maps on the left side of Figure 6 present the trajectories of the expectations for the countries for which we obtain better forecasting results with nonlinear models (ANNs): Austria, Germany, Italy, the Netherlands and Portugal for the question about the country’s general situation regarding overall economy; Denmark, Finland, Greece, Italy, the Netherlands and Portugal for the question about the country's general situation regarding capital expenditures; and Austria, Germany, Finland, Sweden, Italy, the Netherlands and Portugal for the question about the country's general situation regarding private consumption. The rest of the countries are analyzed in the three maps on the right side, which present the trajectories of the expectations of agents from the countries for which time series models show a better forecasting performance.

As it can bee seen, the trajectories on the maps of the left side of Figure 6 show abrupt oscillations between the white area an the grey area, while the opposite is true for the trajectories on the three maps of the right side. As a result it follows that in countries where agents' expectations smoothly move within the grey area, time series models are more suitable for forecasting purposes. Conversely, in countries with abrupt changes in agents' expectations, nonlinear models such as ANNs are preferable for modelling expectations. 
Figure 6. Cluster of countries regarding the behaviour of experts' expectations

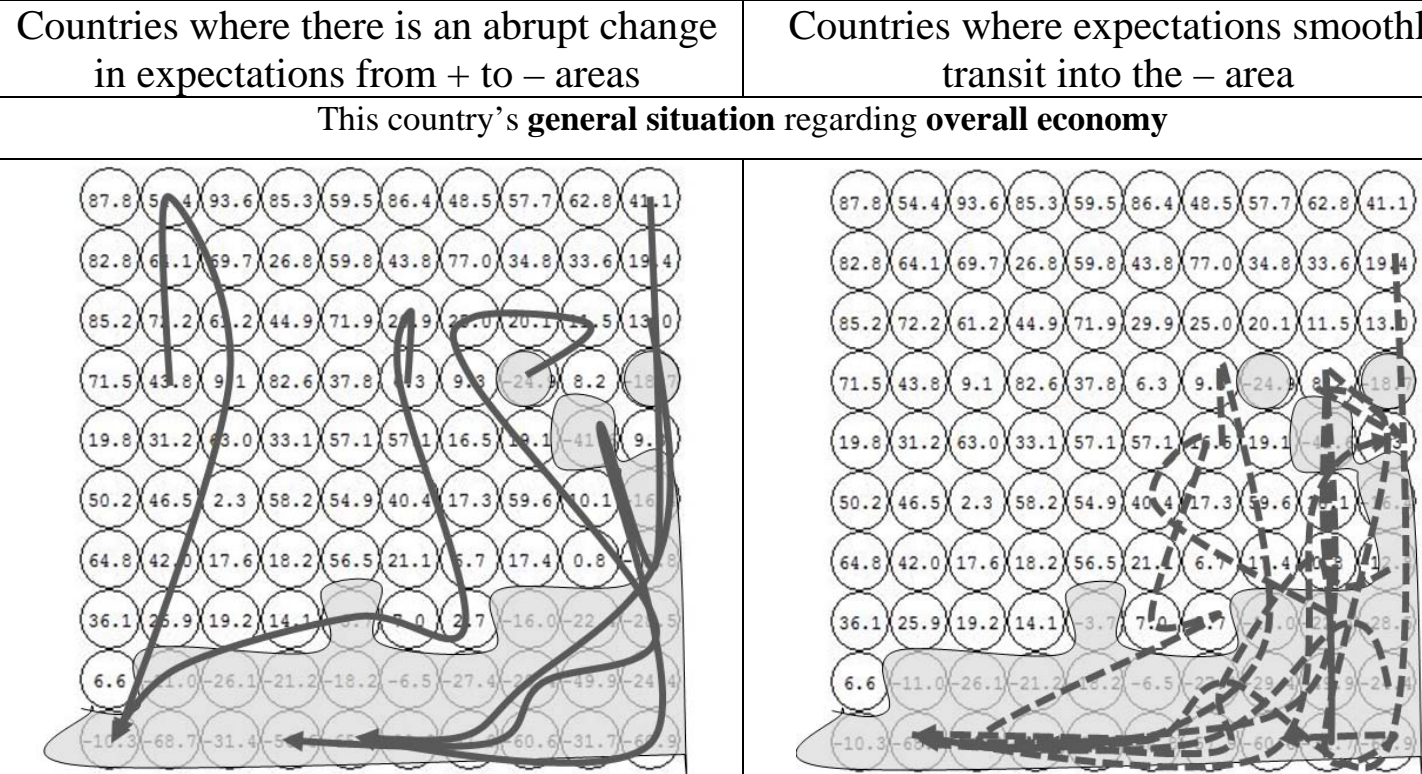

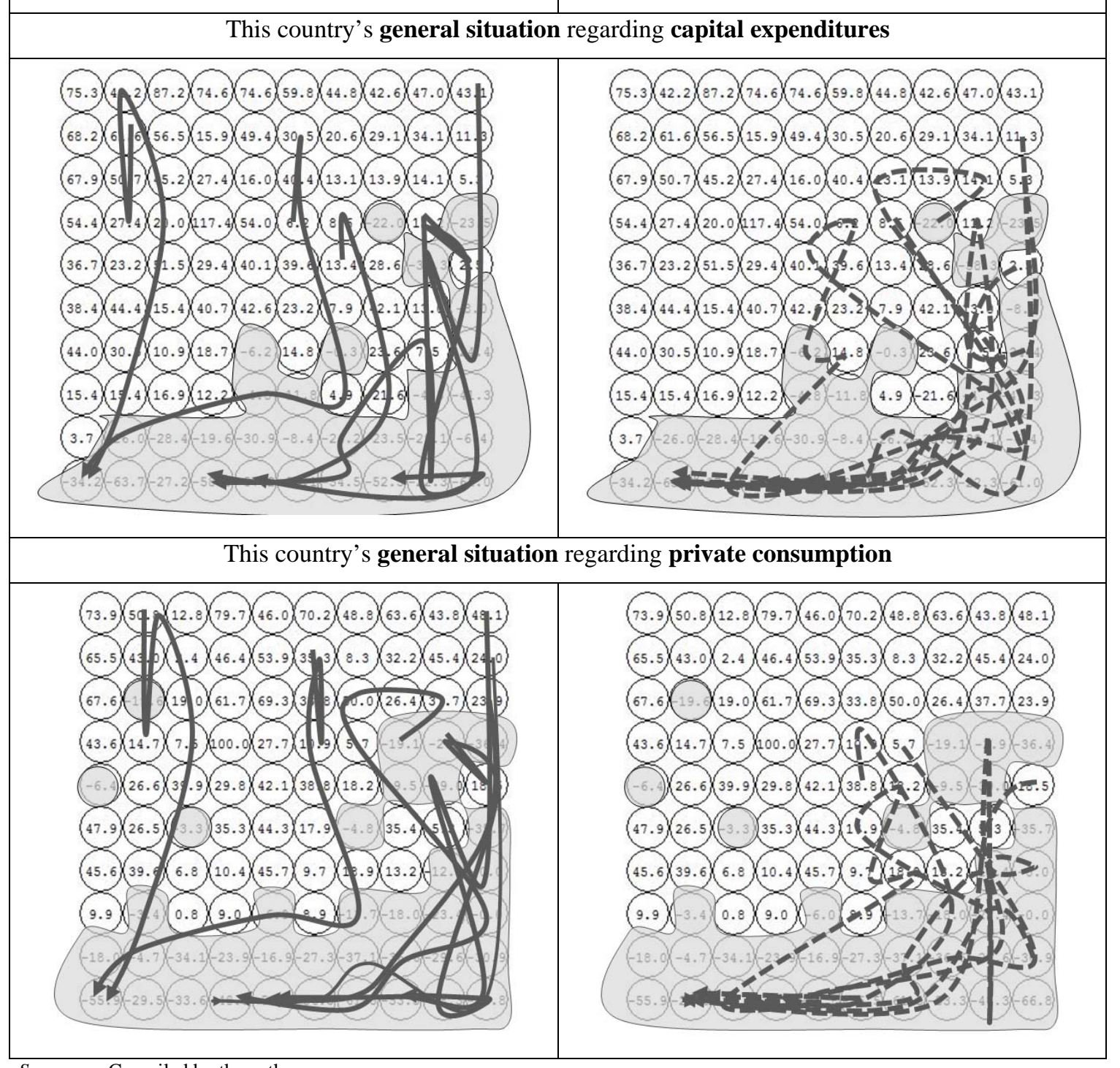

Source: Compiled by the authors. 
Using the financial crisis of 2008 as a benchmark, Figure 6 allows us to classify countries into two clusters: those that show a progressive anticipation of the imminent crisis, and those where expectations show a more erratic path prior to reaching a consensus on the entry into recession. On the one hand, we find that Italy, the Netherlands and Portugal systematically fall within the second category for all three questions (the country's general situation regarding overall economy, capital expenditures and private consumption). This result may be indicating a bias a bias toward optimism on the part of agents in some countries. On the other hand, Belgium, Denmark, France, Greece, Ireland, Spain and the United Kingdom present more stable expectations, showing a smooth transition from the period previous to the recession to the post-crisis quarters.

\section{SUMMARY AND CONCLUSIONS}

Anticipating economic expectations has become essential to assess the current state of the economy. Nevertheless there is not consensus on the most appropriated method to forecast expectations. This study aims to determine how different patterns in the evolution of agents' perceptions before impending shocks influence the type of model to forecast expectations. With this aim we use the forecasting results presented by Claveria and Torra (2013), who generate predictions of survey expectations for fourteen European countries and compare the forecasting accuracy of an Artificial Neural Network (ANN) model to that of three different time series models (AR, ARIMA and SETAR), and incorporate them into a Self-Organizing Map (SOM) analysis of agents' expectations at the beginning of the financial crisis of 2008.

This framework allows us to overlap both sources of information and cluster the fourteen European countries according to behaviour of their agents' expectations during the pre and post-crisis quarters. As a result we find that in countries where agents' expectations progressively anticipate the imminent shock, time series models are more suitable for forecasting purposes. Conversely, in countries where expectations show a more erratic path prior to reaching a consensus on the entry into recession, ANNs are more appropriate for modelling expectations.

The contribution of this study to the economic literature is twofold. On the one hand, it is the first attempt to use Self-Organizing Maps to represent patterns of behavior in 
survey expectations. This technique allows us to visualize high-dimensional data and to cluster countries regarding the evolution of expectations before an impending shock. On the other hand, by combining the SOM representations with the forecasting results of survey expectations, we find that more complex methods can attain a higher forecasting accuracy than time series models when expectations present a nonlinear behaviour. These result shed light on the best way to model expectations.

Nevertheless, this study is not without its limitations. Repeating the experiment using micro data would help to refine the results. By extending the analysis to other countries and to the rest of the questions of the survey, one could test the robustness of the results. Another question to be considered in further research is whether the implementation of Gaussian process regression or machine learning models such as Support Vector regression, may improve the forecasting performance of AI-based economic forecasting.

\section{Acknowledgements}

We wish to thank Ann Stangl and Johanna Plenk at the Ifo Institute for Economic Research in Munich for providing us the data used in the study. This work was supported by the Ministerio de Economía y Competitividad under the SpeechTech4All Grant (TEC2012-38939-C03-02).

\section{REFERENCES}

Adya, M. and Collopy, F. (1998) How effective are neural networks at forecasting and prediction? A review and evaluation. Journal of Forecasting 17: 481-495.

Anderson, O. (1951) Konjunkturtest und Statistik. Allgemeines Statistical Archives 35: 209-220.

Arcienagas-Rueda, I. E. and Arcienagas, F. (2009) SOM-based data analysis of speculative attacks’ real effects. Intelligent Data Anlysis 13: 261-300.

Bahmanyar, A.R. and Karami, A. (2014) Power system voltage stability monitoring using artificial neural networks with a reduced set of inputs. Electrical Power and Energy Systems 58. 246-256.

Biart, M. and Praet, P. (1987) The contribution of opinion surveys in forecasting aggregate demand in the four main EC countries. Journal of Economic Psychology 8. 409-428. 
Breitung, J. and Schmeling, M. (2013) Quantifying survey expectations: What's wrong with the probability approach? International Journal of Forecasting 29: 142-154.

Buchen, T. and Wohlrabe, K. (2013) Forecasting with many predictors: Is boosting a viable alternative? Economic Letters 113: 16-18.

Cang, S. and Yu, H. (2014) A Combination Selection Algorithm on Forecasting. European Journal of Operational Research 234: 127-139.

Celotto, E., Ellero, A., Ferretti, P. (2012) Short-medium Term Tourist Services Demand Forecasting with Rough Set Theory. Procedia Economics and Finance 3: 62-67.

CESifo World Economic Survey (2011), Volume 10, No. 2, May 2011.

Chen, K. (2011) Combining Linear and Nonlinear Model in Forecasting Tourism Demand. Expert Systems with Applications 38: 10368-10376.

Chu, F. (2008) A Fractionally Integrated Autoregressive Moving Average Approach to Forecasting Tourism Demand. Tourism Management 29: 79-88.

Clar, M., Duque, J.C. and Moreno, R. (2007) Forecasting business and consumer surveys indicators - a time-series models competition. Applied Economics 39: 2565-2580.

Claveria, O. (2010) Qualitative survey data on expectations. Is there an alternative to the balance statistic?. In A. T. Molnar (ed.) Economic Forecasting (pp. 181-190). Nova Science Publishers, Hauppauge NY.

Claveria, O., Pons, E. and Ramos, R. (2007) Business and consumer expectations and macroeconomic forecasts. International Journal of Forecasting 23: 47-69.

Claveria, O., Pons, E. and Suriñach, J. (2006) Quantification of expectations. Are they useful for forecasting?. Economic Issues 11: 19-38.

Claveria, O. and Torra, S. (2013) Forecasting Business surveys Indicators: Neural Networks vs. Time Series Models. AQR Working Papers 12: 1-28.

Claveria, O., Monte, E. and Torra, S. (2014) Tourism Demand Forecasting with Neural Networks Models: Different Ways of Treating Information. International Journal of Tourism Research. Forthcoming.

Claveria, O., Monte, E. and Torra, S. (2016)A New Forecasting Approach for the Hospitality Industry International Journal of Contemporary Hospitality Management, 28 (2). Forthcoming.

Clements, M.P. and Smith, J. (1999) A Monte Carlo study of the forecasting performance of empirical SETAR models. Journal of Applied Econometrics 14: 123-141.

Cybenko G. (1989) Approximation by superpositions of a sigmoidal function. Mathematical Control, Signal and Systems 2: 303-314.

Deboeck, G. and Kohonen, T. (1998) Visual Explorations in Finance with Self-Organizing Maps. Springer, London.

Diebold, F.X. and Rudebusch, G.D. (1989) Scoring the leading indicators. Journal of Business 62: 369-391. 
Eklund, T., Back, B., Vanharanta, H. and Visa, A. (2008) Evaluating a SOM-based financial benchmarking tool. Journal of EmergingTechnologies in Accounting 5: 109-127.

Feng, L. and Zhang, J. (2014) Application of artificial neural networks in tendency forecasting of economic growth. Economic Modelling 40: 76-80.

Fioramanti, M. (2008) Predicting sovereign debt crises using artificial neural networks: a comparative approach. Journal of Financial Stability 4: 149-164.

Franses, P.H., Kranendonk, H.C. and Lanser, D. (2011) One model and various experts: Evaluating Dutch macroeconomic forecasts. International Journal of Forecasting 27: 482495.

Funahashi, K. (1989) On the approximate realization of continuous mappings by neural networks. Neural Networks 2: 183-192.

Ghonghadze, J. and Lux, T. (2009) Modelling the dynamics of EU economic sentiment indicators: An inter-action based approach. Kiel Working Paper, 1487. Institut für Weltwirtschaft, Kiel.

Goh, C., Law, R., Mok, H.M. (2008) Analyzing and Forecasting Tourism Demand: A Rough Sets Approach. Journal of Travel Research 46: 327-338.

Graff, M. (2010) Does a multi-sectoral design improve indicator-based forecasts of the GDP growth rate? Evidence from Switzerland. Applied Economics 42: 2759-2781.

Guizzardi, A. and Stacchini, A. (2015) Real-time Forecasting Regional Tourism with Business Sentiment Surveys. Tourism Management 47: 213-223.

Hendry, D.F. and Clements, M.P. (2003) Economic forecasting: some lessons from recent research. Economic Modellig 20: 301-329.

Hill, T., Marquez, L., O’Connor, M. and Remus, W. (1994) Artificial neural network models for forecasting and decision making. International Journal of Forecasting 10: 5-15.

Hornik, K., Stinchcombe, M. and White, H. (1989) Multilayer feedforward networks are universal approximations. Neural Networks 2: 359-366.

Kaastra, I. and Boyd, M. (1996) Designing a neural network for forecasting financial and economic time series. Neurocomputing 10: 215-236.

Kang, S. and Cho, S. (2014) Approximating support vector machine with artificial neural network for fast prediction. Experts Systems with Applications 41: 4989-4995.

Kao L.J., Chiu C.C., Lu, C.J. and Chang, C.H. (2013) A hybrid approach by integrating wavelet-based feature extraction with MARS and SVR for stock index forecasting. Decision Support Systems 54: 1228-1244.

Kaushika, N.D., Tomar, R.K and Kaushik, S.C. (2014) Artificial neural network model based on interrelationship of direct, diffuse and global solar radiations. Solar Energy 103: 327-342.

Kock, A.B. and Teräsvirta, T. (2011) Forecasting with nonlinear time series models in M.P. Clements and D.F. Hendry (eds.) Oxford Handbook of Economic Forecasting (pp. 61-87). Oxford University Press, Oxford. 
Kock, A.B. and Teräsvirta, T. (2014) Forecasting performances of three automated modelling techniques during the economic crisis 2007-2009. International Journal of Forecasting In Press.

Kohonen, T. (1982) Self-Organized Formation of Topologically Correct Feature Maps. Biological Cybernetics 43: 59-69.

Kohonen, T. (2001) Self-Organized Maps. Springer, Berlin.

Kon, S., and Turner, L.L. (2005) Neural Network Forecasting of Tourism Demand. Tourism Economics 11: 301-328.

Lahiri, K. and Zhao, Y. (2015) Quantifying Survey Expectations: A Critical Review and Generalization of the Carlson-Parkin method. International Journal of Forecasting 31: 5162.

Lin, C., Chen, H., Lee, T. (2011) Forecasting Tourism Demand Using Time Series, Artificial Neural Networks and Multivariate Adaptive Regression Splines: Evidence from Taiwan. International Journal of Business Administration 2: 14-24.

Liu, Y. and Weisberg, R. H. (2005) Patterns of Ocean Current Variability on the West Florida Shelf Using the Self-organizing Map, Journal of Geophysical Research 110: C06003, 1-12.

Lu, C-J. and Wang, Y. W. (2010) Combining independent component analysis and growing hierarchical self-organizing maps with support vector regression in product demand forecasting. International Journal of Production Economics 128: 603-613.

Lui, S., Mitchell, J. and Weale, M. (2011) The utility of expectational data: firm-level evidence using matched qualitative-quantitative UK surveys. International Journal of Forecasting 27: 1128-1146.

Marghescu, D., Sarlin, P., Liu, P. (2010) Early-warning analysis for currency crises in emerging markets: a revisit with fuzzyclustering. Intelligent Systems in Accounting, Finance and Management 17: 143-165.

Mitchell, J. (2002) The use of non-normal distributions in quantifying qualitative survey data on expectations. Economics Letters 76: 101-107.

Mitchell, J., Smith, R. and Weale, M. (2002) Quantification of qualitative firm-level survey data. Economic Journal 112: 117-135.

Mitchell, J., Smith, R. and Weale, M. (2005) Forecasting manufacturing output growth using firm-level survey data. The Manchester School 73: 479-499.

Nakamura E. (2005) Inflation forecasting using a neural network. Economics Letters 86: 373378.

Pai, P., Hung, K. and Lin K. (2014) Tourism demand forecasting using novel hybrid system. Expert Systems with Applications 41: 3691-3702.

Palmer, A., Montaño, J.J. and Sesé, A. (2006) Designing an artificial neural network for forecasting tourism time-series. Tourism Management 27: 781-790. 
Parigi, G. and Schlitzer, G. (1995) Quarterly forecasts of the Italian business-cycle by means of monthly economic indicators. Journal of Forecasting 14: 117-141.

Pérez-Rodríguez, J.V., Ledesma-Rodríguez, F. and Torra-Porras, S. (2009). Purchasing power parity and nonlinear adjustment. Applied Economics Letters 16: 35-38.

Pérez-Rodríguez, J.V., Torra-Porras, S. and Andrada-Félix, J. (2005) STAR and ANN models: Forecasting performance on the Spanish IBEX35 stock index. Journal of Empirical Finance 12: 490-509.

Qi, M. (2001) Predicting US recessions with leading indicators via neural network models. International Journal of Forecasting 17: 383-401.

Resta, M. (2012) Graph mining based SOM: a tool to analyze economic stability. In: Johnsson, M. (Ed.), Applications of Self-Organizing Maps (pp. 1-25). InTech Open, Croatia.

Sarlin, P. and Peltonen, T. A. (2013) Mapping the state of financial stability. Journal of International Financial Markets, Institutions \& Money 26: 46-76.

Robinzonov, N., Tutz, G. and Hothorn, T. (2012) Boosting techniques for nonlinear time series models. AStA Advances in Statistical Analysis 96: 99-122

Sarlin, P. and Marghescu, D. (2011) Visual predictions of currency crises using self-organizing maps. Intelligent Systems in Accounting, Finance and Management 18: 15-38.

Sermpinis, G., Dunis, C., Laws, J. And Stasinakis, C. (2012) Forecasting and trading the EUR/USD exchange rate with stochastic Neural Network combination and time-varying leverage. Decision Support Systems 54: 316-329.

Song, H. and Li, G. (2008) Tourism demand modelling and forecasting - a review of recent research. Tourism Management 29: 203-220.

Stangl, A. (2008) Essays on the measurement of economic expectations. Dissertation. Universität München, Munich.

Stock, J. H. and Watson, M.W. (2003) Forecasting output and inflation: the role of asset prices. Journal of Economic Literature 41: 788-829.

Swanson, N. R. and White, H. (1997) Forecasting economic time series using flexible versus fixed specification and linear versus nonlinear econometric models. International Journal of Forecasting 13: 439-461.

Tsaur, S., Chiu, Y. and Huang C. (2002) Determinants of Guest Loyalty to International Tourist Hotels: A Neural Network Approach. Tourism Management 23: 397-405.

Tsaur, R. and Kuo, T. (2011) The Adaptive Fuzzy Time Series Model with an Application to Taiwan's Tourism Demand. Expert Systems with Applications 38: 9164-9171.

Wehrens, R. and Buydens, L. M. C. (2007) Self-and super-organizing maps in R: the Kohonen package. Journal of Statistical Software 21: 1-19.

Wasserman, P. D. (1989) Neural computing: Theory and practice. Van Nostrand Reinhold, New York. 
Yu, G., Schwartz, Z. (2006) Forecasting Short Time-Series Tourism Demand with Artificial Intelligence Models. Journal of Travel Research 45: 194-203.

Zhang, G.P. and Qi, M. (2005) Neural network forecasting for seasonal and trend time series. European Journal of Operational Research 160: 501-514. 


\section{$\mathbb{\Phi}_{\mathbb{Q}}|\mathrm{R}| \mathrm{E}|\mathrm{A}|$}

Institut de Recerca en Economia Aplicada Regional i Públic

Research Institute of Applied Economics

WEBSITE: www.ub-irea.com·CONTACT: irea@ub.edu

\section{AQR}

Grup de Recerca Anàlisi Quantitativa Regional

Regional Quantitative Analysis Research Group

WEBSITE: www.ub.edu/aqr/•CONTACT: aqr@ub.edu

\section{Universitat de Barcelona}

Av. Diagonal, 690 • 08034 Barcelona 